\title{
The role of tryptase and anti-type II collagen antibodies in the pathogenesis of idiopathic epiretinal membranes
}

This article was published in the following Dove Press journal:

Clinical Ophthalmology

29 June 2015

Number of times this article has been viewed

\author{
Tsunehiko Ikeda' \\ Kimitoshi Nakamura ${ }^{2}$ \\ Hidehiro Oku' \\ Seita Morishita' \\ Masanori Fukumoto' \\ Hiroyuki Suzuki' \\ Teruyo Kida' \\ Taeko Horie' \\ Tetsuya Sugiyama ${ }^{3}$ \\ Shinji Takai ${ }^{4}$ \\ 'Department of Ophthalmology, \\ Osaka Medical College, Takatsuki \\ City, Osaka, Japan; ${ }^{2}$ Nakamura Eye \\ Clinic, Nagano, Japan; ${ }^{3}$ Nakano Eye \\ Clinic, Kyoto, Japan; ${ }^{4}$ Department \\ of Pharmacology, Osaka Medical \\ College, Takatsuki City, Osaka, Japan
}

Purpose: To investigate the pathogenesis of idiopathic epiretinal membrane (ERM) from a biochemical perspective, the relationships between ERM and tryptase activity, a serine protease, and the levels of anti-type II collagen (anti-IIC) antibodies in the serum.

Patients and methods: Vitreous samples for measurement of tryptase activity were obtained from 54 eyes of 54 patients who underwent a vitrectomy for vitreoretinal disease, ie, 14 eyes of 14 patients with idiopathic macular hole, 14 eyes of 14 patients with proliferative diabetic retinopathy (PDR), 13 eyes of 13 patients with ERM, and 13 eyes of 13 patients with rhegmatogenous retinal detachment (RRD). Tryptase activity was measured by spectrophotometry. Anti-IIC antibodies were measured in the serum obtained from 17 patients with ERM, eight patients who underwent cataract surgery, 12 patients with PDR, and nine patients with RRD. In these 46 patients, the anti-IIC antibodies were measured using a Human/Monkey Anti-Type I and Type II Collagen IgG Assay Kit.

Results: Vitreal tryptase activity (mean \pm standard deviation [SD]) in macular hole, PDR, ERM, and RRD was $0.0146 \pm 0.0053,0.0018 \pm 0.0018,0.0166 \pm 0.0046$, and $0.0117 \pm 0.0029 \mathrm{mU} / \mathrm{mg}$ protein, respectively. Vitreal tryptase activity was significantly higher in macular hole and ERM than in PDR and RRD $(P<0.05$, Fisher's protected least significant difference). The serum levels of anti-IIC immunoglobulin $\mathrm{G}(\mathrm{IgG})$ antibody (mean $\pm \mathrm{SD}$ ) in ERM, cataract surgery, PDR, and RRD were $58.222 \pm 30.986,34.890 \pm 18.165,55.760 \pm 26.008$, and $35.453 \pm 12.769$ units $/ \mathrm{mL}$, respectively. The serum levels of anti-IIC IgG antibody were significantly higher in ERM and PDR than in cataract surgery and RRD $(P<0.05$, Fisher's protected least significant difference, two-sided).

Conclusion: In the pathogenesis of ERM, increased vitreal tryptase activity may be involved in tissue fibrosis, and elevated serum anti-IIC antibodies may lead to an immune response at the vitreoretinal interface, thus resulting in membrane formation.

Keywords: idiopathic epiretinal membranes, tryptase, anti-type II collagen antibodies, vitrectomy, mast cells

\section{Introduction}

Idiopathic epiretinal membrane (ERM) most often occurs in middle-aged and older adults, and ERM causes metamorphopsia and decreased visual acuity. There is currently no effective pharmacotherapy for ERM, the only treatment option being vitrectomy. The pathogenesis of ERM has been postulated to involve cell proliferation and extracellular matrix accumulation on vitreous gel that forms the posterior wall of a posterior precortical vitreous pocket, ${ }^{1}$ and/or a break in the inner limiting membrane due to posterior vitreous detachment, which then leads to migration and proliferation of glial cells in the sensory retina..$^{2-4}$ However, almost no other research, other than
Correspondence: Tsunehiko lkeda Department of Ophthalmology, Osaka Medical College, 2-7 Daigaku-cho, Takatsuki City, Osaka 569-8686, Japan Tel +8I 726846434 Fax +8I 726820995

Email tikeda@poh.osaka-med.ac.jp 
from a morphological perspective, has been performed in regard to ERM.

Our group previously reported that in cases of idiopathic macular hole (MH), which, like ERM, also occurs specifically at the macular region, the activity of chymase, a serine protease, is increased in the vitreous..$^{5}$ In addition, we proposed a hypothesis that undifferentiated stem cell-like cells exist in the fovea, and that by chymase-induced apoptosis, there is dysfunction of these undifferentiated cells, which can lead to $\mathrm{MH}^{6}$

Meanwhile, in patients with diabetic retinopathy (DR), serum anti-type II collagen (anti-IIC) antibody levels are increased, and with the progression of DR, blood-retinal barrier disruption occurs, leading to contact between serum anti-IIC antibodies and type II collagen in the vitreous. This causes an immune response, which may also be involved in the pathogenesis of DR. ${ }^{7}$

As an extension of this previous research, ${ }^{5-7}$ the relationships between ERM and the activity of tryptase, a serine protease, and the levels of anti-IIC antibodies were investigated.

\section{Patients and methods}

\section{Measurement of vitreal tryptase activity}

For the measurement of tryptase activity, vitreous samples were obtained from 54 eyes of 54 patients who underwent vitrectomy for vitreoretinal disease, ie, 14 eyes of 14 patients with $\mathrm{MH}, 14$ eyes of 14 patients with proliferative DR (PDR), 13 eyes of 13 patients with ERM, and 13 eyes of 13 patients with rhegmatogenous retinal detachment (RRD).

For sample collection, an irrigation port was placed, and before starting irrigation, $0.5-1.0 \mathrm{~mL}$ of an undiluted vitreous gel sample was obtained using a vitreous cutter. The vitreous samples were frozen immediately and stored. Written informed consent was obtained from all patients prior to their involvement in the study, and this study was approved by the Ethics Committee of Osaka Medical College, Takatsuki City, Osaka, Japan.

For the measurement of tryptase activity, N-p-Tosyl-GlyPro-Arg-p-nitroanilide was dissolved in dimethyl sulfoxide and diluted with reaction buffer $(0.06 \mathrm{M}$ Tris) for use as the substrate solution. The enzyme solution (vitreous sample) was added to the reaction buffer, allowed to react with the substrate solution for 1 hour at $37^{\circ} \mathrm{C}$, and the absorbance was then measured at $420 \mathrm{~nm}$.

Fisher's protected least significant difference (PLSD) was used for statistical analysis, and a $P$-value of $<0.05$ was considered statistically significant.

\section{Anti-IIC IgG antibody measurement in the serum}

Anti-IIC antibodies were measured in serum obtained from 17 patients with ERM, eight patients who underwent cataract surgery (CAT), 12 patients with PDR, and nine patients with RRD. In these 46 patients, the anti-IIC antibodies were measured using a Human/Monkey Anti-Type I and Type II Collagen IgG Assay Kit (Chondrex Inc., Redmond, WA, USA). Patients were excluded from the study if their blood samples were positive for rheumatoid factor, if they had symptoms of rheumatoid arthritis, or if they had inflammatory eye diseases. Patients who had previously undergone any other eye surgeries were also excluded.

The obtained blood samples were centrifuged, with the blood serum diluted 20-fold using sample/standard dilution buffer. The samples were then diluted 20 -fold by adding $125 \mu \mathrm{L}$ of $10 \mathrm{mM}$ ethylenediaminetetraacetic acid $/ 0.02 \%$ sodium azide/phosphate buffered saline and $250 \mu \mathrm{L}$ of sample/ standard dilution buffer. The samples were then stored at $-20^{\circ} \mathrm{C}$ until the experiment was performed. The levels of anti-IIC immunoglobulin $\mathrm{G}$ ( $\mathrm{IgG}$ ) antibody in the serum were measured using a Human/Monkey Anti-Type I and Type II Collagen IgG Assay Kit (Chondrex Inc.) according to the manufacturer's instructions. To correct for any false-positive reactions caused by the adhesive immunoglobulin contained in the samples, a unique nonspecific background value was first determined for each of the individual samples by using antigen non-coated wells. This was then subtracted from the value determined in antigen-coated wells in order to obtain the correct result for the antigen-antibody reaction.

Fisher's PLSD was used for statistical analysis, and a $P$-value of $<0.05$ was considered statistically significant.

\section{Results}

\section{Vitreal tryptase activity in vitreoretinal diseases}

The 54 eyes of the 54 patients who underwent vitrectomy included 14 eyes of $14 \mathrm{MH}$ patients (six males and eight females; mean age: $66.1 \pm 5.3$ years), 14 eyes of 14 PDR patients (nine males and five females; mean age: $59.0 \pm 13.7$ years), 13 eyes of 13 ERM patients (four males and nine females; mean age: $63.8 \pm 8.9$ years), and 13 eyes of $13 \mathrm{RRD}$ patients (ten males and three females; mean age: $53.8 \pm 7.5$ years). All patient ages are expressed as mean \pm standard deviation (SD).

Vitreal tryptase activity (mean $\pm \mathrm{SD}$ ) in $\mathrm{MH}$, PDR, ERM, and RRD was $0.0146 \pm 0.0053,0.0018 \pm 0.0018$, $0.0166 \pm 0.0046$, and $0.0117 \pm 0.0029 \mathrm{mU} / \mathrm{mg}$ protein, respectively. Vitreal tryptase activity was significantly higher in 


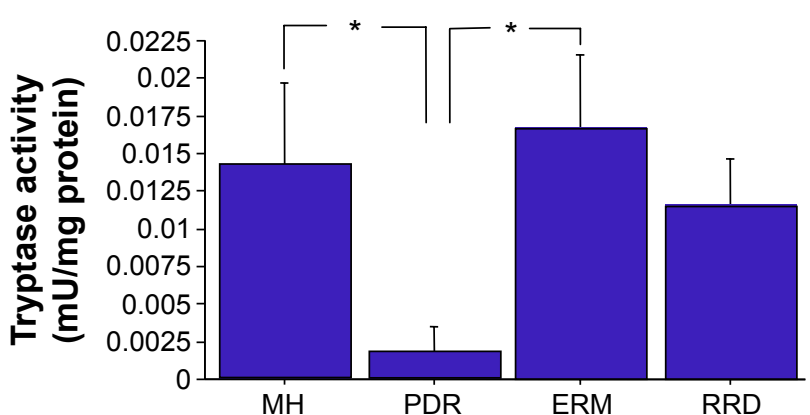

Figure I Tryptase activity in vitreoretinal diseases.

Note: Tryptase activity was found to be significantly higher in $\mathrm{MH}$ and ERM than in PDR and RRD $(* P<0.05$, Fisher's PLSD test, two-sided).

Abbreviations: $\mathrm{MH}$, macular hole; ERM, epiretinal membrane; PDR, proliferative diabetic retinopathy; RRD, rhegmatogenous retinal detachment; PLSD, protected least significant difference.

MH and ERM than in PDR and RRD $(P<0.05$, Fisher's PLSD, two-sided) (Figure 1).

Optical coherence tomography (OCT) showed that the foveal thickness increased in all ERM patients; however, we did not confirm by use of fluorescein fundus angiography in all cases. Judging by use of OCT alone, obvious macular edema was revealed in only two cases. Moreover, no relationships were found between the presence of macular edema and the intravitreal tryptase levels.

We also investigated the presence of posterior vitreous detachment (PVD) via the patients' medical records. The results revealed PVD in five cases and no PVD in eight cases. Moreover, no relationships were found between the presence of PVD and the intravitreal tryptase levels.

In addition, we carefully evaluated the severity of ERM by fundus photograph and OCT imaging. The results showed no relationships between the severity of ERM and the intravitreal tryptase levels.

\section{Anti-IIC IgG antibody measurement in the serum}

For the measurement of anti-IIC IgG antibody in the serum, blood samples were obtained from 46 patients, ie, 17 patients with ERM, eight patients with CAT, 12 patients with PDR, and nine patients with RRD. The serum levels of anti-IIC IgG antibody (mean \pm SD) in ERM, CAT, PDR, and RRD were 58.222 $\pm 30.986,34.890 \pm 18.165,55.760 \pm 26.008$, and $35.453 \pm 12.769$ units $/ \mathrm{mL}$, respectively. The serum levels of anti-IIC IgG antibody were significantly higher in ERM and PDR than in CAT and RRD $(P<0.05$, Fisher's PLSD, two-sided) (Figure 2).

We also evaluated the levels of anti-IIC antibodies according to the presence/absence of PVD, and no

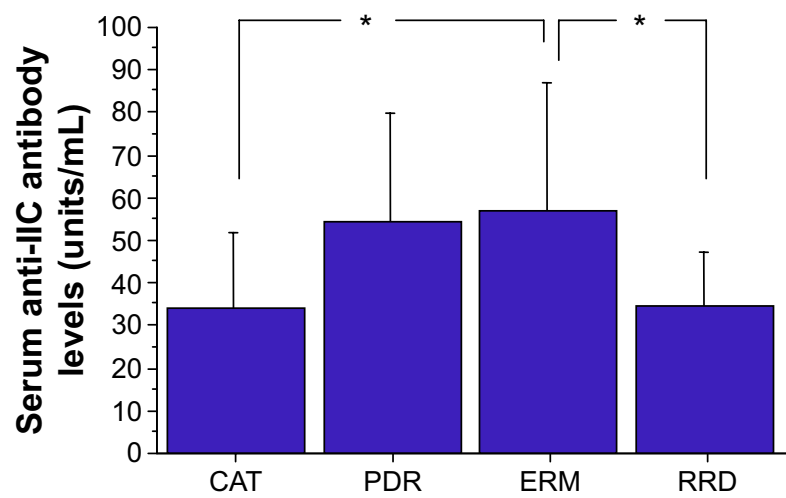

Figure 2 Serum anti-IIC antibody levels in the patients with ERM, PDR, CAT, and RRD.

Note: Serum anti-IIC antibody levels were found to be significantly higher in ERM and PDR than in CAT and RRD ( $* P<0.05$, Fisher's PLSD test, two-sided).

Abbreviations: anti-IIC, anti-type II collagen; ERM, epiretinal membrane; PDR, proliferative diabetic retinopathy; CAT, cataract surgery; RRD, rhegmatogenous retinal detachment; PLSD, protected least significant difference.

relationships were found between the presence of PVD and the levels of anti-IIC antibodies.

\section{Discussion}

Kishi and Shimizu proposed that the pathogenesis of ERM involved cell proliferation and extracellular matrix accumulation on vitreous gel that forms the posterior wall of the posterior precortical vitreous pocket. ${ }^{1}$ ERM is a disease usually seen in older adults. The progression of PVD that occurs with aging can cause rupture of the inner limiting membrane (the basement membrane of Muller cells), and the migration and proliferation of retinal glial cells from this site may lead to ERM. ${ }^{2}$ In fact, histological examination of ERM in samples obtained at vitrectomy reportedly showed numerous glial cells. ${ }^{3}$ Yamashita et al reported that ERMs are the result of anomalous PVD with vitreoschisis, leaving the outermost layer of posterior vitreous cortex attached to the macula. ${ }^{4}$ However, much remains unclear in regard to the pathogenesis of ERM. For example, the reason why these types of proliferative changes specifically occur at the macular region or why ERM of the macular region may recur even after removal of membranes at vitrectomy, remains unknown.

Our group previously reported that chymase, which is a serine protease produced by mast cells, is possibly involved in the pathogenesis of $\mathrm{MH}$, which is also a macular disease. ${ }^{5}$ Chymase has a variety of effects, including 1) the conversion of angiotensin I to angiotensin II; 2) the conversion of bound transforming growth factor beta 1 (TGF- $\beta 1$ ) to free TGF- $\beta 1$, which leads to cleavage of procollagen and the formation of collagen; 3) the activation of matrix metalloproteinases, which 
degrade the extracellular matrix; and 4) the inactivation of tissue inhibitors of metalloproteinases, which promotes collagen degradation. ${ }^{8-10}$ Thus, chymase is probably involved in tissue remodeling by virtue of a combination of two actions, namely, collagen production and degradation. In addition, chymase promotes fibroblast proliferation, and chymase induces apoptosis of cells with relatively low differentiation, which have the ability to dedifferentiate into other cells such as vascular smooth muscle cells, bronchial smooth muscle cells, and cardiomyocytes. ${ }^{11-13}$

In a study using monkey eyes, we also previously reported a higher number of nestin-positive cells in the fovea compared to other retinal areas, and that with intravitreal injection of chymase into monkey eyes, there were TdT-mediated dUTP nick end labeling (TUNEL)-positive cells in the fovea. ${ }^{6}$ In other words, in the pathogenesis of $\mathrm{MH}$, increased vitreal chymase activity may be involved in the apoptosis of undifferentiated cells in the fovea.

The present study involving the measurement of tryptase activity is an extension of our previous research. ${ }^{5-7}$ Our findings showed that tryptase activity was significantly higher in ERM and $\mathrm{MH}$ than in the other two vitreoretinal diseases. Some patients with $\mathrm{MH}$ also have ERM, thus suggesting the possibility of a common pathogenic mechanism in both of these vitreomacular interface diseases.

Serine proteases such as chymase and tryptase are produced in mast cells, and the roles of mast cells in tissue fibrosis, tissue remodeling, and angiogenesis have recently attracted attention. ${ }^{14,15}$ The existence of mast cells in the eye, including the choroid, ciliary body, conjunctiva, and sclera, has also been reported. ${ }^{16}$ At present, it is unknown which tissues in the eye produce chymase and tryptase in the vitreous, however, uveal tissues such as the choroid and ciliary body are likely candidates. There are two types of mast cells: tryptase-positive cells and tryptase/chymase-positive cells. In regard to the localization of mast cells in the choroid, many tryptase/chymase-positive mast cells are reportedly found in the posterior portion of the ocular fundus. ${ }^{16}$

Both chymase and tryptase are serine proteases, and both probably have actions that influence tissue fibrosis and angiogenesis. ${ }^{17-20}$ However, chymase is predominantly involved in apoptosis and tryptase is predominantly involved in tissue fibrosis. The degree of activity of both chymase and tryptase may influence the development of $\mathrm{MH}$ or ERM. Based on our findings, chymase activity was high in $\mathrm{MH}$, while tryptase activity was not that high in $\mathrm{MH}$; however, the activities of both the enzymes were high in ERM.
It is unclear if ERM exhibits only fibrotic changes, and not endothelial cell proliferation or neovessel formation. The macular region is an avascular area, and this specific environment might prevent endothelial cell proliferation in the ERM.

The findings of the present study also showed elevated serum anti-IIC antibody levels in patients with ERM. We previously reported elevated anti-IIC antibody levels in patients with DR, and that the blood-retinal barrier disruption leads to contact between serum anti-IIC antibodies and type II collagen in the vitreous, thus causing an immune response which may be involved in the pathogenesis of DR. ${ }^{6}$ In ERM as well, an immune response primarily in the macular region, which involves a similar mechanism, may lead to the formation of membrane-like tissue. In fact, histological examination in ERM has shown the existence of immune cells such as lymphocytes and macrophages. ${ }^{21}$

As described in previous reports, because cartilage and the vitreous, where type II collagen is present, are both avascular tissues, type II collagen has the property of being a sequestered antigen that can escape surveillance by immune cells circulating in blood throughout the body, thus leading to immunological tolerance. ${ }^{22-24}$ In chronic rheumatoid arthritis (RA), this immunological tolerance is lost for some reason, and various autoantibodies (including anti-IIC antibodies) form and joint tissue is destroyed by an autoimmune response. ${ }^{25-27}$ Moreover, serum anti-IIC antibody levels, besides those in chronic RA, are reportedly also elevated in osteoarthritis, relapsing polychondritis, and Meniere's disease. ${ }^{28,29}$ For this reason, the patients who had symptoms of RA were excluded in the present study if their blood samples were positive for rheumatoid factor.

The three tissues where type II collagen is present, namely, joints, the inner ear, and vitreous, contain synovial fluid, lymph, and vitreous fluid, respectively. These body fluids are sequestered from immune cells in the blood by the blood-joint barrier, blood-labyrinth barrier, and blood-retinal (ocular) barrier, respectively. With chronic hyperglycemia in patients with DR, it is known that the blood-retinal barrier is disrupted, vascular permeability is increased, and macular edema can occur. With progression of chronic RA and Meniere's disease, hydrarthrosis and endolymphatic hydrops are known to occur, and in these diseases as well, there is a possibility of barrier function disruption, increased vascular permeability, and a loss of immunological tolerance.

Tryptase is not only involved in tissue fibrosis, ${ }^{30-31}$ but it is also involved, via matrix metalloproteinases-2, in the degradation of type IV collagen, the chief component of 
basement membranes. ${ }^{32}$ Tryptase is also reported to damage vascular endothelial cells. ${ }^{33}$ In patients with ERM, mast cells are activated by some mechanism, and tryptase, which is produced by these mast cells, can disrupt the inner limiting membrane (basement membrane of Muller cells), which then promotes the migration of glial cells in the sensory retina. In addition, vascular endothelial cells in the blood-retinal barrier are damaged, anti-IIC antibodies can diffuse into the vitreous cavity, and an immune response is elicited at the vitreoretinal interface, thus leading to membrane formation. In fact, fluorescein fundus angiography in ERM is reported to show leakage of fluorescein and macular edema in areas of membrane formation. ${ }^{34,35}$ This finding suggests damage of vascular endothelial cells in the blood-retinal barrier. In this study, no relationships were found between the presence of PVD, the severity of the ERM and the intravitreal tryptase levels, and the levels of anti-IIC antibodies. Due to the small number of patients involved in this clinical study, further investigations are needed to evaluate the relevant questions.

Although further studies are necessary to elucidate why mast cell production of tryptase is increased, as well as why serum anti-IIC antibodies are increased, in patients with ERM, the present findings suggest that at least these two biologically active substances may be involved in the pathogenesis of ERM. In ERM, a disease for which there is very little prior biochemical research data, the results of this present study may serve as a clue to further clarify the pathogenesis of the disease. Of note, previous studies have shown that toll-like receptors, which play an important role in natural immunity, are also expressed in mast cells. ${ }^{36-39}$ Thus, further investigation of the association between ERM and natural immunity is needed.

\section{Acknowledgment}

The authors wish to thank John Bush for reviewing the manuscript.

\section{Disclosure}

The authors report no conflicts of interest in this work.

\section{References}

1. Kishi S, Shimizu K. Oval defect in detached posterior hyaloid membrane in idiopathic preretinal macular fibrosis. Am J Ophthalmol. 1994; 118(4):451-456.

2. Foos RY. Vitreoretinal juncture; epiretinal membranes and vitreous. Invest Ophthalmol Vis Sci. 1977;16(5):416-422.

3. Bringmann A, Wiedemann P. Involvement of Müller glial cells in epiretinal membrane formation. Graefes Arch Clin Exp Ophthalmol. 2009; 247(7):865-883.
4. Yamashita T, Uemura A, Sakamoto T. Intraoperative characteristics of the posterior vitreous cortex in patients with epiretinal membrane. Graefes Arch Clin Exp Ophthalmol. 2008;246(3):333-337.

5. Maruichi M, Oku H, Takai S, et al. Measurement of activities in two different angiotensin II generating systems, chymase and angiotensinconverting enzyme, in the vitreous fluid of vitreoretinal diseases: a possible involvement of chymase in the pathogenesis of macular hole patients. Curr Eye Res. 2004;29(4-5):321-325.

6. Sugiyama T, Katsumura K, Nakamura K, et al. Effects of chymase on the macular region in monkeys and porcine Muller cells: probable involvement of chymase in the onset of idiopathic macular holes. Ophthalmic Res. 2006;38(4):201-208.

7. Nakaizumi A, Fukumoto M, Kida T, et al. Measurement of serum and vitreous concentrations of anti-type II collagen antibody in diabetic retinopathy. Clinical Ophthalmology. 2015;9:543-547.

8. Kofford MW, Schwartz LB, Schechter NM, Yager DR, Diegelmann RF, Graham MF. Cleavage of type I procollagen by human mast cell chymase initiates collagen fibril formation and generates a unique carboxylterminal propeptide. J Biol Chem. 1997;272:7127-7131.

9. Lees M, Taylar DJ, Woolley DE. Mast cell proteinases activate precursor forms of collagenase and stromelysin, but not of gelatinase A and B. Eur J Biochem. 1994;223:171-177.

10. Frank BT, Rossall JC, Caughey GH, Frang KC. Mast cell tissue inhibitor of metalloproteinase- 1 is cleaved and inactivated extracellularly by

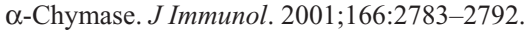

11. Leskinen MJ, Lindstedt KA, Wang Y, Kovanen PT. Mast cell chymase induces smooth muscle cell apoptosis by a mechanism involving fibronectin degradation and disruption of focal adhesions. Arterioscler Thromb Vasc Biol. 2003;23:238-243.

12. Leskinen M, Wang Y, Leszczynski D, Lindstedt KA, Kovanen PT. Mast cell chymase induces apoptosis of vascular smooth muscle cells. Arterioscler Thromb Vasc Biol. 2001;21:516-522.

13. Hara M, Matsumori A, Ono K, et al. Mast cells cause apoptosis of cardiomyocytes and proliferation of other intramyocardial cells in vitro. Circulation. 1999;100:1443-1449.

14. Johnson JL, Jackson CL, Angelini GD, George SJ. Activation of matrixdegrading metalloproteinases by mast cell proteases in atherosclerotic plaques. Arterioscler Thromb Vasc Biol. 1998;18:1707-1715.

15. Boesiger J, Tsai M, Maurer M, et al. Mast cell can secrete vascular permeability factor/vascular endothelial cell growth factor and exhibit enhanced release after immunoglobulin E-dependent upregulation of fc epsilon receptor I expression. J Exp Med. 1998;188:1135-1145.

16. May CA. Mast cell heterogeneity in the human uvea. Histochem Cell Biol. 1999;112:381-386.

17. Ribatti D, Nico B, Maxia C, et al. Neovascularization and mast cells with tryptase activity increase simultaneously in human pterygium. J Cell Mol Med. 2007;11(3):585-589.

18. Blair RJ, Meng H, Marchese MJ, et al. Human mast cells stimulate vascular tube formation. Tryptase is a novel, potent angiogenic factor. J Clin Invest. 1997;99(11):2691-2700.

19. Hallgren J, Estrada S, Karlson U, Alving K, Pejler G. Heparin antagonists are potent inhibitors of mast cell tryptase. Biochemistry. 2001; 40(24):7342-7349.

20. Hiromatsu Y, Toda S. Mast cells and angiogenesis. Microsc Res Tech. 2003;60(1):64-69.

21. Charteris DG, Hiscott P, Grierson I, Lightman SL. Proliferative vitreoretinopathy. Lymphocytes in epiretinal membranes. Ophthalmology. 1992; 99(9):1364-1367.

22. Stein-Streilein J, Streilein JW. Anterior chamber associated immune deviation (ACAID): regulation, biological relevance, and implications for therapy. Int Rev Immunol. 2002;21(2-3):123-152.

23. Sonoda KH, Sakamoto T. The analysis of systemic tolerance elicited by antigen inoculation into the vitreous cavity: vitreous cavity-associated immune deviation. Immunology. 2005;116(3):390-399.

24. Klareskog L, Johnell O, Hulth A, Holmdahl R, Rubin K. Reactivity of monoclonal anti-type II collagen antibodies with cartilage and synovial tissue in rheumatoid arthritis and osteoarthritis. Arthritis Rheum. 1986; 29(6):730-738. 
25. Cook AD, Rowley MJ, Mackay IR, Gough A, Emery P. Antibodies to type II collagen in early rheumatoid arthritis. Correlation with disease progression. Arthritis Rheum. 1996;39(10):1720-1727.

26. Fujii K, Tsuji M, Kitamura A, Murota K. The diagnostic significance of antitype II collagen antibody assay in rheumatoid arthritis. Int Orthop. 1992; 16(3):272-276.

27. Nandakumar KS, Svensson L, Holmdahl R. Collagen type II specific monoclonal antibody-induced arthritis in mice. Am J Pathol. 2003; 163(5):1827-1837.

28. Joliat T, Seyer J, Bernstein J, et al. Antibodies against a 30 kilodalton cochlear protein and type II and IX collagens in the serum of patients with inner ear diseases. Ann Otol Rhinol Laryngol. 1992;101(12): 1000-1006.

29. Yajima K, Nakamura A, Sugahara A, Takai T. FcgammaRIIB deficiency with Fas mutation is sufficient for the development of systemic autoimmune disease. Eur J Immunol. 2003;33(4):1020-1029.

30. Levi-Schaffer F, Piliponsky AM. Tryptase, a novel link between allergic inflammation and fibrosis. Trends Immunol. 2003;24(4):158-161.

31. Cairns JA. Inhibitors of mast cell tryptase beta as therapeutics for the treatment of asthma and inflammatory disorders. Pulm Pharmacol Ther. 2005;18(1):55-66.

32. Yamamoto K, Kumagai N, Fukuda K, Fujitsu Y, Nishida T. Activation of corneal fibroblast-derived matrix metalloproteinase- 2 by tryptase. Curr Eye Res. 2006;31(4):313-317.
33. Mäyränpää MI, Heikkilä HM, Lindstedt KA, Walls AF, Kovanen PT. Desquamation of human coronary artery endothelium by human mast cell proteases: implications for plaque erosion. Coron Artery Dis. 2006; 17(7):611-621.

34. Maguire AM, Margherio RR, Dmuchowski C. Preoperative fluorescein angiographic features of surgically removed idiopathic epiretinal membranes. Retina. 1994;14(5):411-416.

35. Klein BR, Hiner CJ, Glaser BM, Murphy RP, Sjaarda RN, Thompson JT. Fundus photographic and fluorescein angiographic characteristics of pseudoholes of the macula in eyes with epiretinal membranes. Ophthalmology. 1995;102(5):768-774.

36. Sandig H, Bulfone-Paus S. TLR signaling in mast cells: common and unique features. Front Immunol. 2012;3:185.

37. Yamashita M, Nakayama T. Progress in allergy signal research on mast cells: regulation of allergic airway inflammation through toll-like receptor 4-mediated modification of mast cell function. J Pharmacol Sci. 2008;106(3):332-335.

38. Okayama Y. Mast cell-derived cytokine expression induced via Fc receptors and Toll-like receptors. Chem Immunol Allergy. 2005;87: 101-110.

39. Marshall JS, McCurdy JD, Olynych T. Toll-like receptor-mediated activation of mast cells: implications for allergic disease? Int Arch Allergy Immunol. 2003;132(2):87-97.
Clinical Ophthalmology

\section{Publish your work in this journal}

Clinical Ophthalmology is an international, peer-reviewed journal covering all subspecialties within ophthalmology. Key topics include: Optometry; Visual science; Pharmacology and drug therapy in eye diseases; Basic Sciences; Primary and Secondary eye care; Patient Safety and Quality of Care Improvements. This journal is indexed on

\section{Dovepress}

PubMed Central and CAS, and is the official journal of The Society of Clinical Ophthalmology (SCO). The manuscript management system is completely online and includes a very quick and fair peer-review system, which is all easy to use. Visit http://www.dovepress.com/ testimonials.php to read real quotes from published authors. 